\title{
Multi-usage des ressources et mobilités : l'intensification dans une zone humide sahélienne. Le lac Tchad vu par sa fenêtre camerounaise
} Thèse de Doctorat (PhD), Ecole doctorale ABIES, AgroParisTech, Laboratoire Prodig (UMR 8586), 2016

\section{Charline Rangé}

\section{OpenEdition}

\section{Journals}

Édition électronique

URL : http://journals.openedition.org/anthropodev/458

DOI : 10.4000/anthropodev.458

ISSN : 2553-1719

Éditeur

APAD - Association pour l'anthropologie du changement social et du développement

\section{Édition imprimée}

Date de publication : 1 juillet 2016

Pagination : 199-200

ISBN : 797-10-93476-03-2

ISSN : 2276-2019

\section{Référence électronique}

Charline Rangé, « Multi-usage des ressources et mobilités : I'intensification dans une zone humide sahélienne. Le lac Tchad vu par sa fenêtre camerounaise ", Anthropologie \& développement [En ligne], 44 | 2016, mis en ligne le 01 décembre 2016, consulté le 23 septembre 2020. URL : http:// journals.openedition.org/anthropodev/458; DOI : https://doi.org/10.4000/anthropodev.458

\section{(c) ()}

La revue Anthropologie \& développement est mise à disposition selon les termes de la Licence Creative Commons Attribution 4.0 International. 


\title{
Multi-usage des ressources et mobilités : l'intensification dans une zone humide sahélienne
}

\author{
Le lac Tchad vu par sa fenêtre camerounaise
}

\author{
Charline Rangé ${ }^{1}$ \\ Thèse de Doctorat (PhD), Ecole doctorale ABIES, AgroParisTech, Labora- \\ toire Prodig (UMR 8586), 2016
}

\section{Résumé}

La thèse porte sur les dynamiques d'exploitation et de gestion des ressources naturelles du lac Tchad, dans sa partie camerounaise. Celle-ci a en effet fait l'objet d'une extraordinaire mise en valeur depuis la découverte de vastes terres de décrue, liée au retrait des eaux lors des sécheresses des années 1970-1980. Quasi espace vierge au milieu du $X X^{\mathrm{e}}$ siècle, le lac est aujourd'hui densément peuplé et cosmopolite, et il nourrit les marchés urbains de la sous-région. Dans cet espace rythmé par des jeux saisonniers de crue et de décrue éminemment variables, l'absence de critères socio-ethniques dans l'accès au foncier et la grande fluidité des régulations foncières ont conduit à une profonde imbrication des activités agricoles, halieutiques et pastorales dans l'espace et dans le temps. Cette imbrication traduit un processus d'intensification du mode d'exploitation au niveau territorial qui a abouti à des performances économiques remarquables. Dans cette zone humide transfrontalière, l'incertitude hydro-écologique, économique et démographique a été intégrée au fonctionnement "normal » du système agraire et des territoires. Aujourd'hui, c'est l'incertitude foncière et politique qui menace la région. Elle résulte des conflits de pouvoirs locaux, constitutifs du rapport de l'Etat aux populations, et des politiques agricoles qui mettent l'accent sur l'agriculture d'entreprise et la simplification des écosystèmes.

Alors que ces dynamiques paysannes restent occultées dans les discours des décideurs qui continuent à faire de la technicité des grands aménagements la réponse aux enjeux sociétaux complexes, la thèse démontre, chiffres à l'appui, la capacité de ces paysanneries à alimenter les villes, à créer des emplois et augmenter les revenus ruraux, et à assurer une exploitation durable des ressources dans un contexte climatique incertain. Face à la difficulté à décrire la mouvance de l'organisation de l'espace, la thèse propose en outre un modèle graphique innovant de représentation des " espaces-temps » qui permet de spatialiser de façon dyna-

${ }^{1}$ E-mail : charline.range@gmail.com 
mique les pratiques agricoles, pastorales et halieutiques. Enfin, elle questionne les communs environnementaux sous un angle original. Dans le modèle fondateur d'E. Ostrom, la gestion locale des ressources naturelles suppose l'existence de droits exclusifs sur la ressource pour un groupe d'ayants droit bien identifié et une régulation intentionnelle élaborée. Ici, au contraire, c'est en l'absence de groupes pouvant revendiquer une maîtrise foncière exclusive qu'ont émergé des coordinations pratiques (sans organisation explicite et intentionnelle) dans le partage de l'usage de l'espace qui ont évolué pour accompagner la densification du parcellaire et des troupeaux.

La recherche repose sur un important travail de terrain (600 entretiens et observations, des études de cas de conflits fonciers, l'exploitation d'archives, la quantification des productions). Le raisonnement, construit dans l'articulation des échelles, s'inscrit à la croisée de la géographie tropicale française, de l'agriculture comparée et de la socio-anthropologie du foncier, pour étudier ensemble dynamiques agraires, territoriales et foncières. II regarde vers les travaux de la Political Ecology pour confronter discours et processus globaux d'une part et logiques et pratiques locales d'autre part. 